\title{
Aclaraciones a la Novela Social Americana
}

\author{
El arte social
}

\begin{abstract}
$\mathbf{A}$ RTE social, de propaganda o dirigido son términos que, con la connotación expresa o tácita de sinonimia, se identifican corrientemente, en especial en el enjuiciamiento literario. Se dice, por ejemplo, la literatura social de la Unión Soviética, por decir: los escritores soviéticos, dirigidos por la propaganda comunista. Lo social ha llegado a identificarse y a ser comprendido como la aplicación práctica del marxismo en la literatura.

Contra tal costumbre debe recordarse que, aun cuando las teorías marxistas y lo social más o menos antiguo, pueden ser coincidentes, no significan lo mismo, en la literatura, en las artes ni en la vida. Lo social -antiguo o moderno - es cierta labor o cierta orientación, no importa de qué época o escuela, definidora de una colectividad; lo marxista es, por esencia, lo relacionado a la trayectoria y porvenir de una clase, e históricamente lo relativo a la crítica de la burguesía y al ascenso del proletariado como clase sucesora. Gladkov y Cholokhov representan lo social-marxista y así están aceptados; pero Martín Fierro es social sin ser marxista, y $L a$ Virgen de los Cristeros es una fuerte novela social, y su autor, Fernando Robles, es un anti-marxista. $Y$ no perdamos tiempo con los que identifican lo social y lo marxista: ¿deja de ser socialmente definidor Eduardo Mallea, el de la máscula Historia de una pasión argentina, por no aceptar los postulados marxistas? De ninguna manera. Sea cual fuere su tendencia, contribuye a definir un estado social de la Argentina.
\end{abstract}




\section{Intención y asepsia en arte}

El arte social es, pues, un arte intencionado, tendencioso, esclarecedor. El arte social siempre ha existido. En español, por ejemplo, acaso las más antiguas manifestaciones de arte social sean las contenidas en El Romancero. Su origen hay que buscarlo en la épica del pueblo. Los temas han ido evolucionando conforme evoluciona la sociedad. De ahí que lo social no precise de acuñamiento preceptista. Cualquiera reconoce, por modo intuitivo, las diferencias cardinales que hay entre el aséptico y afectadamente impersonal Garcilaso y el humanísimo y sanamente robusto Arcipreste de Hita. Y Cervantes - vayamos rectamente al ejemplo más alto- ¿no es profundamente social y enraizado en lo más auténtico de la tragedia española? Don Quijote, en un noventa por ciento, es libro fustigador, vertebrado, rebelde, anticipista y anti-clásico, en el sentido de que rompe los moldes de la literatura greco-romana, en aquellos días recién exhumados por el renacentismo.

$Y$ téngase en cuenta que así como Cervantes y Lope, el Arcipreste y $\mathrm{El}$ Romancero tienen mucho de literatura social, por lo que se acercan a su pueblo, procurando interpretarlo, igualmente acontece en América, a partir de los copleros anónimos, hasta llegar a esas claras concreciones de un arte social, eminentemente del pueblo, que se llaman El Periquillo Sarniento y Martín Fierro. De modo que, si para representar a una clase, basta decir los nombres de Fray Luis, Herrera, Garcilaso, hombres vueltos de espaldas a las realidades agónicas de su tiempo, para representar a España y América, en la raigambre más íntima de su personalidad, hay que referirse a quienes socavan en las minas del pueblo para extraerle el oro de su emoción y los diamantes de su sensibilidad. Es lo que hacen Cervantes en el Siglo de Oro, Hernández en la Argentina, Lizardi en México, y tantos y tantos más dispersos en la invertebrada América. No considerarlos en su valor social, equivale a negarlos, a la vez que se contribuye a apuntalar el vacilante prestigio de una sociedad que se desmorona o está abocada al trance de su desaparición. 


\section{Lo social y lo moderno}

El arte social es anti-clásico, tomando clásico no en el sentido de cosa antigua, consagrada o buena, sino en su verdadera acepción de lo perteneciente a una clase, es decir, de lo que se relaciona con el patriciado romano y las clases que sucedieron a éste en el disfrute del poder. De ahí que lo social -como anti-clásico- sea típicamente una de las manifestaciones de lo moderno.

Antes de proseguir, es conveniente que definamos nuestro concepto de lo moderno. La modernidad no es cosa vinculada al tiempo, sino a la conducta o al modo. Un arte o un alma son modernos no porque se les avecine a una época determinada, sino porque en cualquier medio o en cualquier época reaccionan conforme a una conducta o modo de ser fluyente y aproximativo a las sustancias. Lo moderno es mutable, intemporal, riesgoso y obedeciendo a conciencia a las modalidades del ser. Lo moderno es, pues, una cierta actitud calitativa tendiente a acoger lo modal, sabiendo que lo es, y ayudando, por todos los medios, a realizarlo.

El problema cardinal de lo moderno entraña lo múltiple y diverso, viniendo a ser lo más esencial y auténtico, es decir, la expresión existencial de lo colectivo frente a la expresión de la clase. El arte y la literatura modernos, cuyo contenido es primordialmente demoledor, destructivo de la precedencia y la inmediatez, deviene en tentativa reconstructora y en germen subconsciente de nuevas formas vitales que desembocan en la interrogación de una nueva edad. De ahí que lo moderno aluda al módulo, al pluralismo, a una cierta índole fluyente de estar, a un estado que no admite precedencia ni sucesiones, porque se realiza y tiene su finalidad en si misma, con modalidad propia, ya sea ésta la de la barbarie o la de la civilización.

\section{Clasicismo y literatura social}

Si el clasicismo tiende a la antisepsia y a considerar a la literatura como problema artístico, para la modernidad, destructora de lo uniforme, la literatura es por esencia un problema humano. Lo clásico es supra-nacional y tiende a un concepto imperialista del arte. Lo moderno, en cambio, conduce a aceptar ir ahondando 
en los módulos de cada nacionalidad. De ahí que lo clásico desnaturalice al hombre y lo moderno sea ante todo de indole telúrica. $\mathrm{El}$ arte en América, mientras permaneció clásico - mejor dicho, mientras se movió bajo el ordenamiento clasicista-, fué un arte esencialmente colonial. El arte devino en arte de sentido americano el día en que comenzó a plantearse problemas de existencia, adquiriendo calidad humana y vinculándose fuertemente a la tierra.

Al convertirse el arte, y en especial la literatura en América, en un retrato de la vida ordinaria, lo social va cobrando cuerpo. La poesía, primero, la novela, después, se vuelven tendenciosas. Lo épico se cotidianiza y el arte intencionado se convierte en arte civil. La modernidad en América se origina en los copleros anónimos, que el folklore va recogiendo por llanadas y serranías. Con la organización de las nacionalidades adviene la literatura cívico-patriótica, que lutego se transforma en ideológica, en naturalista, en liberal socializante, en revolucionaria, pero ante todo, en literatura de expresión telúrica y en vehículo que escoge el mensaje de una humanidad nueva.

Significando la modernidad esencialmente el advenimiento de las variedades nacionales que rompen el esquema clasicista, en ella se contiene, por modo germinal, la voz de los pueblos, hasta entonces aherrojada por el régimen colonial, es decir, por el régimen de clase. Las condiciones sociales influyen, naturalmente, en la génesis del arte moderno. En América comienza a interesar más la realidad que la ficción de la realidad. La literatura se inclina a fijar al hombre centrado en un paisaje. Cada pueblo pugna por descubrir sus perfiles auténticos y por ir desarrollando su carácter, sin perder por eso los ángulos coincidenciales que pueda tener con los demás.

Para referirnos especialmente a la novela -que es donde mejor se observa el fenómeno de lo moderno como hecho social- descubrimos, ante todo, que la novela en América transita por las siguientes etapas: a) romántica, con anticipaciones naturalistas; b) naturalista, con huellas o señales románticas; c) poemático-intelectual y de insurgencia revolucionaria.

\section{Influjo del suelo y del paisaje}

La literatura americana - literatura moderna por antonomasia-, con anticipos o de contenido social, al recorrer el tránsito de 
esas cuatro etapas, tiene de común el hecho de que opera bajo el influjo del suelo y del paisaje. En contraposición a la novela europea, que parece concederlo todo al análisis y a la psicología, tiene su origen en los más profundos sentires de la tierra.

Artistas típicos de esos sentires poderosos del telurismo, configurados por el paisaje y el alma del pueblo, fueron los nuestros, desde José Hernández y Domingo Faustino Sarmiento hasta Jorge Icaza y Ciro Alegría. En sus obras se encuentra la máxima expresión en belleza del sentimiento de teluridad.

En toda la novelística americana -en sus mejores libros y en sus mejores autores- se nota una tentativa de explicar al pueblo, y de explicarlo esencialmente como una consecuencia del contorno natural, es decir, de la influencia psicológica del clima y las impresiones psicológicas del paisaje. Aun en los en apariencia más europeizados novelistas, la irracionalidad, como producto de la influencia telúrica, enciende —allá en el fondo- sus temblorosas hogueras. $\mathrm{Y}$ sin embargo, en lo relativo a este problema, es cosa muy distinta lo que tiene su origen en el paisaje - Facundo, Doña Bárbara, La vorágine - y lo que vinculado fuertemente a la mezquindad o abundancia naturales -Martín Fierro, Huasipungo, El mundo es ancho y ajeno - parte del hombre y de su lucha con la sociedad $y$ con el medio.

\section{Apoteosis y prenuncio}

¿La novela americana nace sólo de la irradiación y la consonancia al paisaje? ¿ No será que una ley oculta preside la alternativa entre la animación mítica de la naturaleza y la indagación, aún moderada, pero ya insinuante, del hombre? La novela americana -la mejor es de índole social- está en ascenso y su ulterior biografía marca una actitud perceptiva de la naturaleza y una experiencia reveladora del alma. $\mathrm{Y}$ así puede codearse la claridad mañanera de un Jorge Isaacs, la eficacia poética de un José Eustasio Rivera y el sentido rebelde, siniestro y escindido de un Alfredo Pareja DíezCanseco. En el uno se asiste a la perespiritualización del paisaje, en el otro a la sensibilización estética de la selva y en el último al paisaje considerado como destino condicionador del hombre.

No se trata aquí de aquilatar, ni siquiera de preferir un novelista a otro. Se trata de situarlos dentro del común perfil americano. Ob- 
jetivamente, puede acontecer que, si los colombianos fueron los númenes del romanticismo y de la tentativa de libertarse por la fuga, el ecuatoriano sea el prenuncio de la proletarización, que ha de inspirar, si no regir, la etapa nueva, la que se está abriendo ahora mismo.

Estando la novela americana condicionada por el paisaje y por el alma, las diferencias que en ella se perfilan pueden condensarse en dos sectores: la costa y la montaña. La novela de la costa es más pictórica, más sensual y retozona, y la de la montaña es, en cuanto a usos y creencias populares, de una fantasía más rica, barroca y fluente que la de los pueblos costeros. La novelística montañosa del Ecuador, de Colombia, de Chile y de Bolivia constituye hasta ahora el campo de experimentación donde se concentra con mayor ímpetu la insurgencia popular, mientras el europeísmo y las delicuescencias esteticistas han mostrado su mayor impulso en Buenos Aires, en Lima y excepcionalmente en México, ciudad de montaña, pero heredera y continuadora acérrima del formalismo colonial, roto sólo a chispazos por manifestaciones indigenistas y por las crónicas novelizadas de la Revolución.

En la gran novelística americana -acaso por el influjo preponderante del paisaje y del alma - triunfa lo dinámico, la embriagutez, el misticismo y la supremacía de la pasión. Se ha dicho que toda nuestra novela es romántica - aun cuando se vierta en cualquier otra tendencia. No. Lo que pasa es que nuestros novelistas están ebrios de telurismo, bebidos de zumos de la tierra y de tendencias instintivas. En esta situación, las cosas pierden su peso, se agrandan, y aun cuando barajen cosas materiales, tienden a la espiritualización.

\section{Auscultación de lo popular y del paisaje}

La novela indoamericana es una novela para hombres activos. Lo que hoy la perfila, lo que la exaltará en un mañana próximo, es el nuevo apetito de irracionalidad, de apasionamiento, de objetividad esclarecedora que el ideal de llaneza de los tiempos actuales trae consigo; es la sed de aproximaciones, no de los conceptos de la angustia, no de la rebeldía del indigenismo; de aproximaciones, es decir, rehumanización y esclarecimiento a la vez, y con destino de entidad única. Llamamos aproximaciones a los aspectos psíqui- 
cos del carácter del pueblo cuando - directa, no simbólicamentepueden ser auscultados. Aquí nos encontramos lo más cerca posible de la embriaguez: nos encontramos en la vecindad esencial de una manera de vivir la naturaleza.

Lejos de mí otorgar a estos conceptos: "novela de la irracionalidad", "novela del apasionamiento", un sentido despreciatorio cualquiera. Reafirmo que aquí se trata de definir, no de emprender valoraciones. Si mis expresiones chocan con una cierta cerrazón dogmática del tecnicismo profesoral o lo contradicen, no veo demérito en sustituirlas por otras que sean equivalentes. Para mí, la novela americana, tal como ahora se la contempla, es una novela para hombres muy machos, mientras que la novela de los últimos cuarenta años de Europa, en su abrumadora mayoría, es una novela para hombres reblandecidos.

Para la novela de la América hispano-lusitana, espiritualizar las cosas no significa desmaterializarlas. Significa, al contrario, apreciar su corazón de humanidad, y apreciarla en su escindimiento y en su angustia, enlazándola con otras venas de lo popular y concediendo a todas las cosas aquel rango supremo de la pasión que se llama el equilibrio telúrico.

La tierra atrae poderosamente al novelista de América. Parece que de esta atracción el hombre puede emanciparse de dos maneras: dominando o disolviéndose ; disolverse es más dramático, pero dominar es más noble. De ahí que nuestra novelística sea o de las formas arrastradas por fuerzas disolutivas, o de las formas que salen mejor templadas después de cada encontronazo.

En la novelística americana, a la naturaleza rara vez se la vive como paisaje, sino como un acoso que rodea realmente al dilucidador. La naturaleza se la vive como paisaje cuando se la goza, y en nuestras novelas cardinales - Martin Fierro, Doña Bárbara, Huasipungo, etc.- se la padece, o se es víctima del inaudito avance de la civilización sobre la barbarie.

De ahí que para hablar de novela auténtica americana sea preciso referirse al pueblo y a calidades populares subordinadas a un valor telúrico sumo que las modela y conforma. En este sentido, muchas novelas pobres en valores literarios obtienen una profunda representación, y en cambio, novelas de alta valoración literaria puede ser que no representen el estado de cultura americano. Con ello se 
abren a las vivencias instintivas de lo popular nuevos horizontes que, en verdad, tódavía están oscurecidos por el velo de lo misterioso.

\section{El rango del hombre en la novela.}

El problema más alto -y también el más difícil- en este conjunto de la novela americana nos lo plantea el hombre. Su vivencia de lo telúrico tiene una importancia distinta para su caracterización, según las directrices de sus preocupaciones y de su fuerza conformadora. Sobre el hombre de acción, el influjo posible de la impresión telúrica pudiera ser insignificante. Cosa muy distinta ocurre con el imaginativo o con el de la más fina sensibilidad para los soplos terrestres.

El rango del hombre en la novela varía según las fases de su desarrollo, por ejemplo, en la de aislarse solitariamente, en la novela romántica; en la de emprender una tentativa de dominación, en la novela naturalista; en la de huir o disolverse, en la novela poemática, y en la de sufrir su destino de pueblo o rebelarse contra el ámbito social, en la novela revolucionaria.

Todas las acciones del hombre en la novela americana están intensamente coloreadas por la vivencia telúrica-desértica, montañosa, llanera, selvática, amazónica, fueguina, etc. Elementos esenciales de la materialidad y del animismo más exaltado contribuyen en todo tiempo a un debatirse angustiado o a una entrega que tiene mucho de escisión. La palabra, por así decirlo, toma de la tierra de origen las peculiaridades pictóricas y conformadoras. ¿Qué trozo de la historia de la novela de América abarca un par de nombres como José Eustasio Rivera y Rómulo Gallegos! En la pintura que hacen de la selva o del llano convierten a la tierra en un trozo de humanidad que se debate entre la civilización y la barbarie. Más que esto no se puede decir, a la postre, de la fuerza interior que sobre el destino ejerce la vivencia telúrica. Nunca antes estuvo una fuerza creadora de la humanidad tan cercana al sentido de la tierra.

\section{La gravitación de la novela}

La novela americana parece regirse por una ley de gravitación a la que en cada etapa de su desarrollo le da el tono en forma serial, 
convirtiendo cada una de ellas en algo así como la sustancia germinadora de la inmediata.

Hemos conocido la hora romántica. Anteayer mismo, en los umbrales formativos de la nacionalidad. En ella se contenía ya el impulso naturalista, así como en éste se contuvieron modalidades románticas. Los libros esenciales de estas dos etapas son: El matadero de Echeverría, Amalia de Mármol, Facundo de Sarmiento, Durante la Reconquista de Blest Gana, El Zarco de Altamirano, Cecilia Valdés de Villaverde, La tierra purpirea de Hudson, Sin rumbo de Cambaceres, Aves sin nido de Clorinda Matto de Turner, El Sargento Felipe de Picón Febres y tantas otras henchidas de una todavía informe emoción social, que cuaja plenamente en esa gran novela en verso que es el Martín Fierro. La novela -a'sí como la poesía y el ensayo- quisieron pronto no ser más que arte; esto se llamó modernismo y también llevó otros nombres. Pero del Modernismo - acaso como continuación costumbrista - van emergiendo los enamorados de lo nativo, en los que ya lo social se desborda. La novela quiere volverse a la tierra, recoge la luz y el ambiente, esculpe caracteres y explora en el conflicto de los pueblos y en el encontronazo del hombre con las desmedidas fuerzas telúricas.

Pocas obras hay en toda la literatura americana tan vivaces como éstas en que la tierra y el hombre se han convertido en centro de atracción. La novela no ambiciona ya sino parecerse a la vida. $Y$ los novelistas se esfuerzan en alcanzar el meollo escindido y sangrante de lo humano. Estos creadores son: Roberto J. Payró, el picaresco y hondo evocador del campo argentino; Lynch, el mago de Los caranchos de la Florida; Manuel Gálvez, el de La maestra normal; Wast, el de La casa de los cuervos; Horacio Quiroga, e1 brujo de Misiones, en quien se infiltra toda el alma selvática; Rodríguez Mendoza, el de Cuesta arriba; Víctor Domingo Silva, el de La pampa trágica; Maluenda, el vigoroso pintor de Escenas de la vida campestre; Eduardo Barrios, el de Juana Lucero; Latorre, eI de On Panta; Edwards Bello, el de Valparaiso, ciudad de viento: Arguedas, el de Raza de bronce; Chirveches, el de La candidatura de Rojas; Canelas, el de Aguas estancadas; Pocaterra, el de Vidas oscuras; Blanco-Fombona, el de El hombre de hierro; Pío Gil, el de El Cabito; Portillo y Rojas, el de La parcela; Carlos Loveira, el de Juan criollo - una de las novelas clave del Continente-, y tantos otros que no menciono, porque no trazo un catálogo sino tan sólo 
un muestrario, y en cuya mayoría bulle una preocupación nacional o continentalista. El pueblo propio o América en su totalidad es en ellos inquietud e incertidumbre viva, en la que apuntan las eclosiones sociales, por cuanto no se preocupan del hombre en abstracto, sino del grupo nacional o del sentido de americanidad.

Es la hora en que empieza, agrandando sus dimensiones, el culto apasionado de las cosas en desequilibrio, el culto preferente a las cosas telúricas y a los hombres que sangran.

Telúrica y más telúrica es la perspectiva. La misma oposición de valores entre el hombre y el medio, entre humanidad y sociedad, entre latifundismo y agrarismo, entre burguesía y proletariado, es conducida, por modo enérgico y bajo la preocupación por la realidad presente y el destino humano, al anchuroso campo de la novela, con sus aristas pedagógicas, políticas y de costumbres.

La novela de hoy no quiere otra cosa que poner un poco de orden en nuestro caos, un aliento definidor en nuestras dimensiones y un poco de esperanzada angustia al margen de las crisis sociales en que el hombre americano se debate.

Definiciones, angustias, esperanzas... Para mí, con nombres distintos, la misma cosa de trascendente y hondo soplo social.

\section{Las tendencias en la novela social}

Mucho nos atrae el sustantivismo de la novela social, mucho cosquillea en nuestro fuero íntimo. Hay que revisar esto. $Y$, al revisar, es conveniente, ante todo, distinguir.

He aquí tres libros: Doña Bárbara, Huasipungo, Paralelo 53 Sur. Su significado, más que distinto, es ya opuesto. Vale aquél por el soberano impulso bárbaro. El segundo, por la profundidad de la tragedia del indio, y el último, por el descubrimiento de las regiones australes del Continente y por la máscula llaneza con que presenta los conflictos. Los tres son estupendas aguafuertes, distinguiéndose aquél por el puro azar físico, el otro porque sus ácidos muerden en los motivos político-económicos, y éste porque muestra una realidad roída por influjos imperialistas que la subconsciencia colectiva adivina.

Doña Bárbara, La vorágine, Los de abajo, son novelas genésicas, anunciadoras de las motivaciones político-sociales, de la pugna 
y el encontronazo en forma dramática y cruenta, del aporte indígena volcado en patetismo arquitectural y de la evasión en busca del tiempo psicológico. Paradójicamente, hay siempre para la novela una medida común. De la Independencia en adelante, el romanticismo. Del romanticismo en adelante, el naturalismo y la exploración psicológica. Luego, la pausa modernista. Del Modernismo acá, prolongándose sin agotamiento, el realismo y el sobre-realismo, interferido por actitudes poemático-intelectuales, en las que también cabe la tentativa de que cada pueblo trate de desarrollar su ser oculto.

A poco que nos detengamos en el asunto, se abre a los ojos de nuestro análisis un panorama complejo. Vemos, por de pronto, que es imposible mantener aisladas a todas las manifestaciones de la novela, despojarlas a todas de la impureza de su social representación. Indigenismo, agrarismo, proletarismo, aparecen, en este sentido, como medidas idénticas. Lo que subsiste, lo que sobrenada de las clasificaciones, son obras y autores muy llanos. La plenitud en el caos es su común denominador. No en vano, en la historia de las actitudes del hombre ante los problemas de lo telúrico, llegan a descubrirse más claramente los signos de la intervención de lo social, que en su historia ante los problemas de lo psíquico.

Mucho de lo que hoy se agita como crisis y combate en la esfera de las cuestiones novelísticas, debería ser concebido como el desbordamiento de una nueva relación entre el hombre y la tierra, que se realiza con tal impulsividad explosiva, precisamente, porque los componentes sociales no han sabido abrir a tiempo la válvula integradora. Con sencillos lamentos sobre el pesimismo de los novelistas actuales, y la divinización de lo brutal, no se elimina este extraordinario hecho psicológico.

El destino del hombre en el trabajo, cada vez más desnaturalizado, y la pugna entre lo personal y lo colectivo, van tomando anchura y profundidad en la novela. E1 hombre, tanto el de las zonas rurales como el de las urbanas, se sobreexcita, padece las vivencias de lo telúrico, se siente arrebatado por rachas cósmicas, y en todos los conflictos se angustia, por desmesura, de manera abrumadora. Aquí rige la regla del estímulo apasionado, que tiende a su aplicación por la experiencia. Las nuevas ordenaciones sociales o su avizoramiento, introducen aquí procesos de expectación con los que es imprescindible contar. Pero en el largo y difícil período de parte de tales ordenaciones resulta inevitable el eruptivismo de lo irracional, 
en formas extrañas y peligrosas. Todo lo elemental que existe en el hombre americano toma su derecho y en la novela adquiere quejumbre o rebeldía de destino.

E1 hombre de América que pugna por expresarse, que anhela una válvula de escape, se refugia en el factor telúrico y la llamada del suelo vuelve a ser muy fuerte. El alma primordial anhela soluciones y distensiones, que no puede ofrecerle el componente activo del conglomerado. Crisis y angustia se sienten como hambre expresiva, en todo caso como algo que no puede alcanzarse sin una dolorosa arquitectura del caos. $Y$ ésta, en última instancia, no en atención a lo personal, sino a lo colectivo. Los valores del medio caen dentro de aquella esfera de lo irracional que depara a los hombres actuales conflictos inconmensurables. Los valores del medio, el alma y el destino se condensan en la vivencia irracional de lo telúrico: ésta es una fuerza magnífica de integración; a ella se adhiere el hombre, impulsado a su autoesclarecimiento, dividido en su totalidad y padeciendo a causa del viejo orden jerárquico.

\section{Factores de la novela social}

Dos factores intervienen en la elaboración de la novela como producto social. Aplicando la terminología que antaño usaran los neoplatónicos y toda clase de gentes de claridad mística, podríamos decir que se trata del Padre y de la Madre de la novela; o si queréis, para valernos de los conceptos caros a Plotino, de los numénicos Noús y Aletheis, en su cardinal oposición y en la continua necesidad de acoplamiento.

La novela americana gira dentro de un sistema esclarecedor de conjuntos populares, y es hija, por una parte, del impulso pasional, telúrico, sensual, que impele al hombre a la recolección y escogitamiento de hechos significativos; por otra parte, de la necesidad de fuga que experimenta el alma humana, constreñida por el medio, y por el deseo de explicarse y unir en un todo coherente las vivencias experimentadas por el hombre y su circunstancia, haciendo inteligible lo sentido como subterráneo y claro lo que acicatea como impulso de rebelión. Yo creo haber confrontado, en el curso de mi estudio, cómo esta necesidad de esclarecimiento se inscribe en el cuadro común de la creación novelística americana, asegurándole su perma- 
nencia como una de las manifestaciones que mejor definen a la tierra y al hombre.

La primera fuerza, dirigida celosamente hacia lo físico, es la curiosidad. A la segunda, por su hambre de expansión, por lo generosa y ecuménica, podemos llamarla exigencia de continentalidad. Un aspecto de la novela lleva como una huella de aquel venero originario: es la parte genésica de ella, la que descubre y quiere explorar, tras de cada acto, tras de cada fenómeno, el atisbo luminoso de una conciencia subțerránea.

Los chispazos del segundo elemento, de lo expansivo y continentalista, hállanse en la parte profunda de la novela, en aquello que le da rango y ordenamiento arquitectónico social. Así la novela reproduce ciertos rasgos de la tierra, otros del hombre, y ambos tienden a la unidad artística.

De ahí se extrae la consecuencia de que la evolución novelística, como empresa de esclarecimiento americano, se la debemos a la pasión, a la curiosidad, al empuje instintivo satánico, siempre indagador de la realidad aún no conformada. En cambio, la exigencia ecuménica representa, ante la evolución novelística, una resistencia, por así decirlo, del Continente invisible. Ella se compone, en cada momento esclarecedor del alma, de la tierra y de la sangre, un cuadro lírico u objetivado, que no quisiera desvertebrarse y que obtiene categoría de mensaje. Pero el cuadro se ve roto a saltos por la pasión curiosa y el inconsciente colectivo; éste reaparece cuando menos se piensa, trayendo la conquista de nuevos territorios.

Hay épocas en la historia de la novela, en que la pasión domina y sujeta relativamente a la curiosidad, épocas en que lo telúrico se sobrépone y en que lo colectivo florece en perjuicio de lo individual. Otras son lo contrario. $\mathrm{Y}$ otras de un ritmo intermedio. Las primeras se nutren del afán explorador, las segundas de la conciencia profunda y las últimas del choque entre el hombre y el medio.

\section{Etapas y etapas}

Desde los puntos de vista a que hemos venido apuntando, las etapas de la novela social en Indoamérica pueden caracterizarse así:

Primer aspecto: etapa del conocimiento telúrico, etapa de la exploración. 
Segundo aspecto: etapa del explosivismo individual-colectivo, etapa de la revolución y de la guerra.

Indigenismo y neo-romanticismo agrario, etapa cohesiva, etapa del descubrimiento y segunda fase de la exploración.

Proletarismo, o sea la nueva etapa explosiva, a la que se incorporan las insurgencias urbanas y de la que emerge lo instintivo.

Podemos decir que si la primera y la tercera aclaran, sobre todo, la segunda y la cuarta construyen y tienden a iniciar un nuevo orden.

\section{Muestrario}

A la novela genésica o del conocimiento telúrico pertenecen: Doña Bárbara de Gallegos, La vorágine de Rivera, El viaje maravilloso de Graça Aranha, Madre América de Max Dickmann, Paralelo 53 Sur de Juan Marín, Cuatro años a bordo de mi mismo de Zalamea Borda, Gente en la isla de Azócar, Contrabando de Enrique Serpa, Los sangurimas de José de la Cuadra, Tierras hechizadas de Costa Du Rels, La gringa de Wyld Ospina y Tilin García de Carlos Enríquez.

La novela de la revolución y de la guerra, o sea el choque del hombre con las fuerzas que tienden a violentarlo, se circunscribe a tres países y abarca tres momentos: la revolución mexicana, la gueIra nicaragüense contra el intervencionismo y la contienda del Chaco. Los frutos característicos de esta etapa y de estos tres momentos son: Los de abajo de Azuela, Panchito Chapopote de Icaza, La Virgen de los Cristeros de Fernando Robles, El águila y la serpiente y Memorias de Pancho Villa de Martín Luis Guzmán, Vámonos con Pancho Villa de Muñoz, Campamento de López y Fuentes, Cartucho de Nellie Campobello, Mi caballo, mi perro $y$ mi rifle y Desbandada de José Rubén Romero, Sangre en el trópico y Los estrangulados de Hernán Robleto, Sangre de mestizos de Augusto Céspedes y Aluvión de fuego de Oscar Cerruto, libros en que se demuestra que un buen novelista tiene forzosamente que ser un buen cronista.

En el indigenismo y el neo-romanticismo agrario, lo que priva es una violencia hecha de problemas, de angustias y dolores comunes, constituyendo todo ello la unidad negativa del hombre en el 
aspecto más crudo de la novelística continental. Las zonas en que el indigenismo se halla ubicado son las del Ecuador, Bolivia, México y Centroamérica, y la novela agraria en la Argentina, Chile, Brasil y Colombia. He aquí algunas obras representativas de esta doble tendencia: Huasipungo de Jorge Icaza, Sumagallpa y Sanagiin de G. Humberto Mata, Don Goyo de Aguilera Malta, Cuentos andinos y Nuevos cuentos andinos de López Albújar, Tempestad en los Andes de Valcárcel, Los perros hambrientos y El mundo es ancho $y$ ajeno de Ciro Alegría, El kilómetro 83 de Díez Canseco, Balseros de Titicaca de Emilio Romero, Rebelión y puna de Hugo Blyn, Tierra y El indio de López y Fuentes, El resplandor de Mauricio Magdaleno, La tierra de los Nahuyacas de Wyld Ospina, El Tigre de Flavio Herrera, Cuentos de barro de Salarrué, Hasta aquí no más de Rojas Paz, La cosecha de Osorio Lizarazo, Sima fecunda de Ricardo Guzmán, Los sertones de Da Cunha, Cacao de Jorge Amado, Calunga de Jorge de Lima, y tantos otros que sería prolijo enumerar,

En cuanto a la etapa de la proletarización o de la insurgencia social, propiamente dicha, se caracteriza por su objetivismo amargo y por su encendida denuncia, Trátase de obras en que se cala hasta la entraña más sangrante de las realidades de cada pueblo, Para clarificarla mayormente, vamos a dividirla en tres aspectos: campesina, urbana y del presidio. A las novelas de la proletarización campestre corresponden: Nuestro pan de Gil Gilbert, Marcos Antilla de Luis Felipe Rodríguez, Colombia, $S$. A. de Antonio García, Toá de César Uribe Piedrahita, Quindio y Oro y miseria de Antonio J. Arango, Aguas estancadas de Juan Modesto Castro, La pampa trágica de Víctor Domingo Silva, Carnalavaca de Andrés Garafulic, Ully de Mariano Latorre, Sangre ovejera de Franco Berzovic, Sub-sole de Baldomero Lillo, Dos pesos de agua de Juan Bosch, Garimpos de Hernán Lima. En las novelas de la proletarización urbana es conveniente situar: Tinieblas de Elías Castelnuovo, Silvano Corujo de Giraldi, Puerto hambre de González Trillo, Puerto América de Albamonte, Blas Cuba de Machado de Assis, Nacha Régules y Hombres en soledad de Gálvez, Canal Zone de Aguilera Malta, Hombres sin presente de Osorio Lizarazo, Baldomera de Díez Canseco, En las calles de Icaza, Banca de Angel F. Rojas, Camarada de Humberto Salvador, El tungsteno de Vallejo, La viuda del conventillo de Alberto Romero, Hijuna y La fábrica de Sepúlveda Ley- 
ton, Angurrientos de Juan Godoy y Los hombres obscuros de Nicomedes Guzmán. En cuanto al tercer aspecto, el de la novela del presidio, lo encontramos en su máximo patetismo en Hombres sin mujer de Carlos Montenegro, Hombres sin tiempo de Alfredo $\mathrm{Pa}$ reja Díez Canseco, Más afuera de Eugenio González, Hombres y rejas de Juan Seoane, Puros hombres de Antonió Arraiz, y en esa tremenda sátira a la justicia que es Estafen! de Juan Filloy.

En la mayoría de estas novelas bulle a borbotones, y emerge con desgarrado y patético acento, una preocupación humana y una ansiedad continentalista. $\mathrm{El}$ hombre, la tierra y el mensaje americano no se consignan en ellas como un hecho objetivo más, sino también y cardinalmente como un estar preocupado, y tampoco como un estar preocupado por módulos literarios, sino como una preocupación telúrica y vital. La tierra y el hombre como preocupación avasalladora, como incertidumbre vital, como un ir disolviéndose en el medio, no se advierte más que en la novela americana y primordialmente en la del sur del Continente, y más primordialmente aún en las zonas de la novela indigenista, primero, ahora en la proletarizante. Entiéndase: no el estar preocupado por el hombre como abstracción o entidad metafísica, no el estar preocupado por sus estados psicológicos, sino la preocupación raizal de sus relaciones con la tierra. La relación desintegrante y reintegradora del hombre y de la tierra podría ser, pues, el distintivo de la novela americana: la relación del hombre con la realidad presente y por los destinos del grupo, del pueblo y aun del Continente.

\section{Gilberto González y Contreras,} La Habana. 